\title{
A Mobility Information Management System for Rural Transportation: A Case Study in Northwest Alabama
}

\author{
Michael D. Anderson \\ The University of Alabama in Huntsville
}

\begin{abstract}
This article presents the development of a Mobility Information Management System (MIMS) within a regional area. The system is designed to provide residents access to important trip information, which can assist them in making informed transportation choices. The final design of the system, demonstrated using a case study of a region in northwest Alabama, includes survey data collected from transportation providers; a database system to maintain, query, and update the information; and an Internet-based system for the public to learn about services provided. The system, after inclusion of all transportation service data, provides a convenient mechanism to educate the public on transportation services and allows transportation service agencies to better understand the services offered in the region and assist passengers in meeting their transportation needs.
\end{abstract}

\section{Introduction}

Rural public transit operators must become more than transit providers-they must become mobility managers with knowledge to assist passengers and arrange 
transportation services beyond their individual system. To accomplish this goal of becoming mobility managers, providers must understand not only their system, but also the interaction of all transportation providers in their region. The heart of this effort would be an information system that contains the elements necessary to manage a trip regionwide using public and private transportation resources. This article presents the development of a MIMS system within a regional area.

At its simplest level, a MIMS is a printed compendium of accurate contact information of all transportation providers regionwide. At its grandest level, it is an Internet-based interactive system that both transportation providers and the public can access and use to chart a trip. This article focuses on the development of a methodology to compile all of this information so it may be used and understood between rural public transit operators and their private sector counterparts; and then understood and used by the public.

This article presents a description of a study area in northwest Alabama, home to 27 individual transportation service coordinators as well as an intercity bus service and a regional airport, and a methodology and design for a rural transportation MIMS. The methodology and design first focuses on what information is needed from the various transportation providers, both public and private. The next item addressed is a database designed to maintain, query, and update the transportation information. Finally, an Internet-based system for the dissemination of transportation information to the public, intended to assist individuals make informed transportation choices, is presented. The article concludes that the Internet-based MIMS provides a convenient mechanism to educate the public on transportation services and allows transportation agencies to better understand the services offered in the region.

\section{Case Study Area}

The case study region selected for the application of the MIMS system consisted of a five-county region in northwest Alabama (shown in Figure 1). The region represented a unique area for the development of MIMS, based on the diverse transportation system, evident through the 27 individual agencies, public and private, responsible for coordinating and/or providing transportation services, as well as intercity bus service and a regional airport. For the 27 individual agencies, there currently exists no coordinating information or technology, Advanced Public Transit System (APTS), to assist in the development of the MIMS system. 


\section{Figure 1. Location of the Case Study in Northwest Alabama}

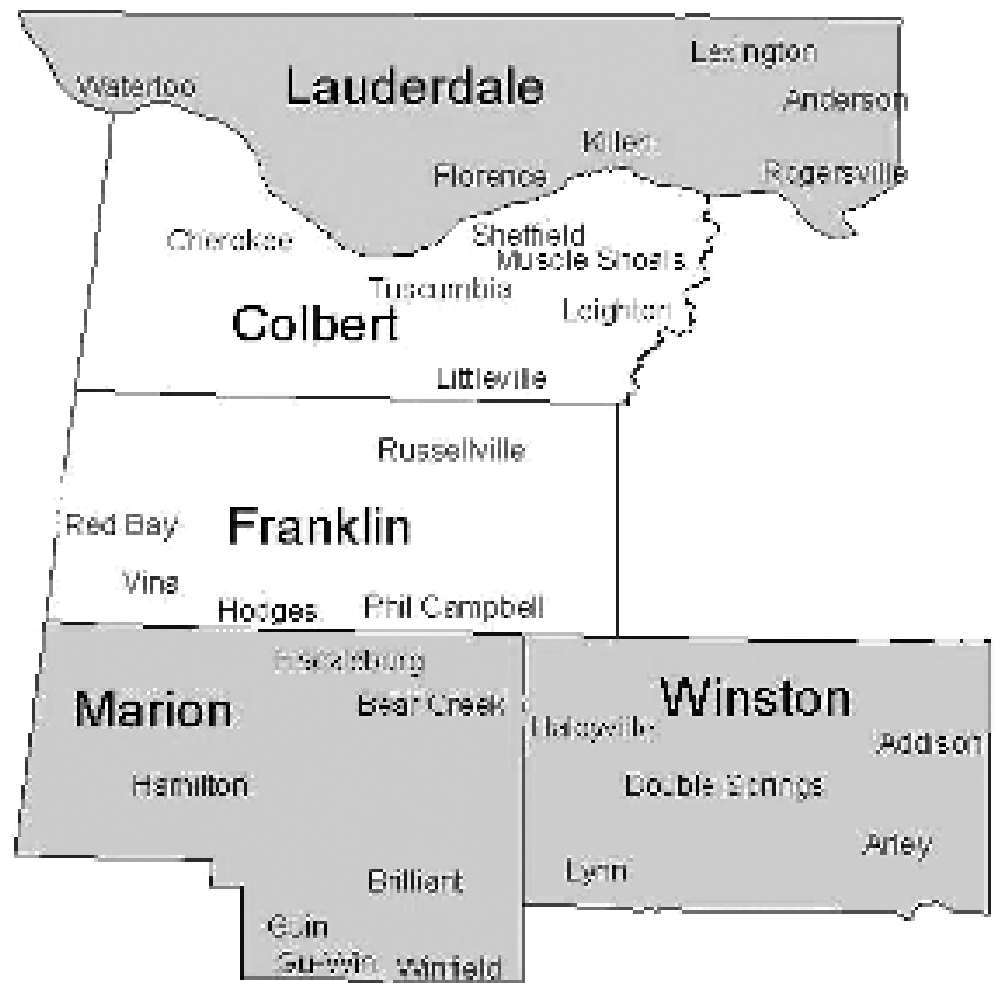

The urban center for the region is the combination of four communities, Florence, Muscle Shoals, Sheffield, and Tuscumbia, known collectively as the Shoals. The region is home to 230,230 people, with 15 percent of the population more than 65 years of age (www.census.gov). The region currently has a 7.0 percent unemployment rate and an $\$ 18,804$ per capita income (http://www.shoalschamber.com/). The major regional employers include health care, government, education, meat processing, textiles, and metallurgical work (http://www.shoalschamber.com/). 


\section{Design of the MMS}

The rural transportation MIMS designed for the northwest Alabama region was developed in three steps. The steps included identification of transportation information, an on-line system allowing transportation providers to enter and modify services offered, and an Internet-based dissemination system allowing the public to access information and make informed travel decisions.

\section{Step 1. Data Collection}

At the heart of any management system, transportation or otherwise, are data. Therefore, it is not surprising that the initial step in MIMS is to collect data related to transportation resources and operation. The data collection effort undertaken for the northwest Alabama region consisted initially of a written survey distributed to all agencies identified by the regional council of local governments as providing transportation services. The format and content of the mail survey was a result of a literature review of several previously used transit surveys and the U.S Department of Transportation's Travel Survey Manual (Tooley et al. 2000; Cambridge Systematics, Inc. 1996; Transit Agency Survey Form [Montana and Colorado). The data collection needs were divided into eight distinct categories:

1. Agency information

2. Operating schedules

3. Technology level

4. Type of service

5. Payment types

6. Qualification criteria

7. Service area

8. Fleet capabilities/demand

The first three categories relate to general agency information. The agency information data included name, address, and contact information. In general, these data are important for communications with agency personnel, but not vital for the MIMS, with the exception of the contact information, which is necessary to users who access the system to arrange transportation services. The data related to operating schedules included days of the week services are provided, hours of service, and general holiday information. The third general agency information re- 
quest related to the technology level of the agency (i.e., software programs, Internet access, agency web pages, and e-mail capability). These questions were asked to determine acceptance of an Internet-based mobility system for disseminating information about transportation services.

The next three categories relate to the service structure and management practices of the agencies. Type of service data show whether the agency provided fixedroute service, demand responsive service, and if service was contracted through another agency. Questions about payment types focused on whether cash or voucher payments were accepted for service and the rates for transportation service. Qualification criteria focused on specific eligibility requirements for service (e.g., youth, elderly, disabled), as well as capabilities for providing service to specific individuals (e.g., disabled people through wheelchair-lift vehicles or elderly persons through door-to-door service with driver assistance).

The final two questions, service area and fleet capabilities/demand, focused on the operations of the transportation service provider. The service area was determined through two methods. First, a listing of the five counties and several cities and towns within the five-county region was provided with a check box on the survey for the agency to select communities where it provided service. Second, a map of the region was provided and agencies were asked to highlight all the areas in which they generally provide service. This service area data is vital for matching potential riders and transportation services. The fleet capabilities/demand questions assessed the agency's ability to transport individuals by asking for the number of buses, how many were wheelchair-lift accessible, and the number of vehicles that would allow them to meet existing needs (if they are not being met).

Preliminary results from the data collection effort indicated that the information supplied by the service providers needed to be presented on a per route basis, not as one aggregated survey per agency. The reasoning behind this was the aggregate information for a single agency might identify service in two communities within the study area; however, the agency was not necessarily offering service between the two communities. Therefore, the items collected from each agency needed to be specific to individual routes operated by the agencies, implying that a single agency could have many routes identified with unique operating schedules, qualifications, payment schedules, and service area. 


\section{Step 2. On-line System for Data Entry and Modification}

The next required element of the MIMS system was on-line data entry and modification capabilities. Based on the results of the data collection effort, all the transportation providers contacted responded that there was sufficient Internet access within their agencies to allow for on-line entry and modification of the travel information. The on-line system was selected because it provided the ability to use a single database file containing the transportation services for the region in a central location that could be accessed remotely. This ability eliminated the need for each agency to maintain its own database file within the agency and allowed each agency to update the file as its service changed, without waiting for any one agency to make the changes, thus helping to ensure the data would not become obsolete. Microsoft Access was selected as the database system for the MIMS as this package was familiar to the agencies and could be interfaced through the Internet (although several other database software packages with Internet capabilities could have been used).

Originally, the database file was developed to mimic exactly the survey questionnaire distributed to the individual agencies. The eight data categories identified on the survey were replicated within an on-line system allowing new agencies wanting to enter the database to complete the information on-line and existing agencies to make changes to their information. However, as was determined during the data collection process, the entry of data needed to be adjusted to reflect individual routes, not necessarily individual agency-level information. To account for this, a system was developed that allowed the agencies to enter items unique to specific routes, without having to enter all of the basic information continually. In addition, the on-line data entry and modification system has been designed with password protection to ensure each agency is capable of altering only its specific information and to ensure the only users entering data into the system are registered agencies.

Registered agencies, upon entering the required username and password, are directed to a series of Internet pages where they can enter or modify route information for the specific type of transportation service offered. All the entry and modification screens are designed to match the dissemination screens in the system. Data entry involves a representative from the transportation agency either entering information into blank entry locations and/or through check boxes. Example screens for entering data for a special needs route and a demand response route are shown in Figures 2 and 3. For modification of existing data, the representative 
from the transportation agency is shown screens similar to the blank data entry screens, but with the existing data displayed and the representative only needing to update the information.

\section{Figure 2. Data Entry Screen for a Special Needs Route}

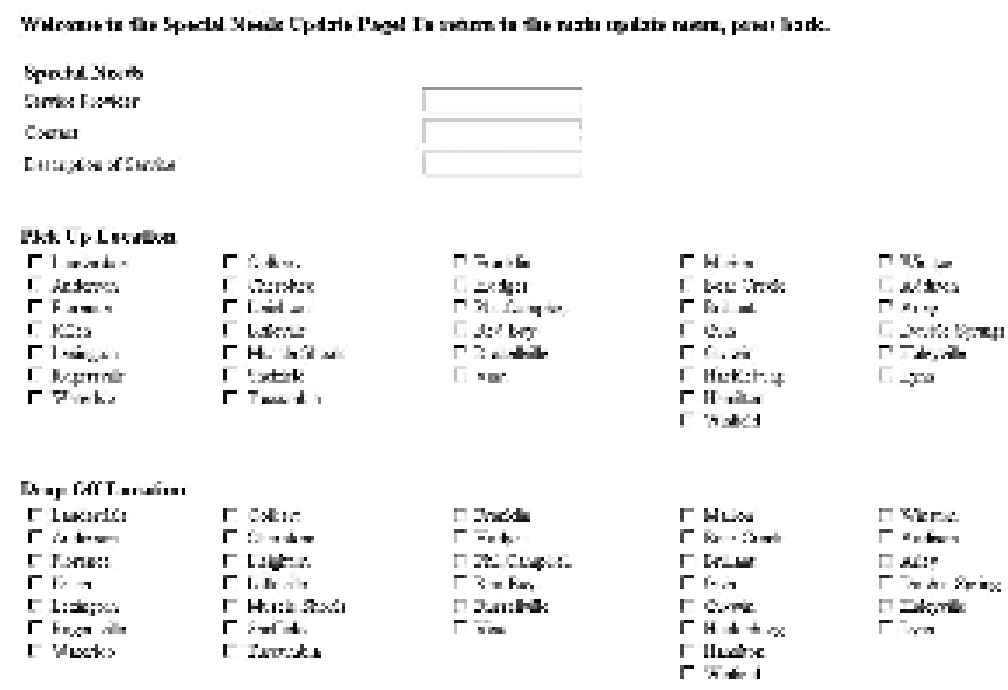




\section{Figure 3. Data Entry Screen for a Demand Response Route}

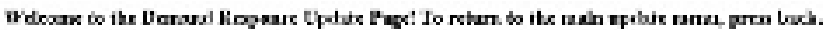
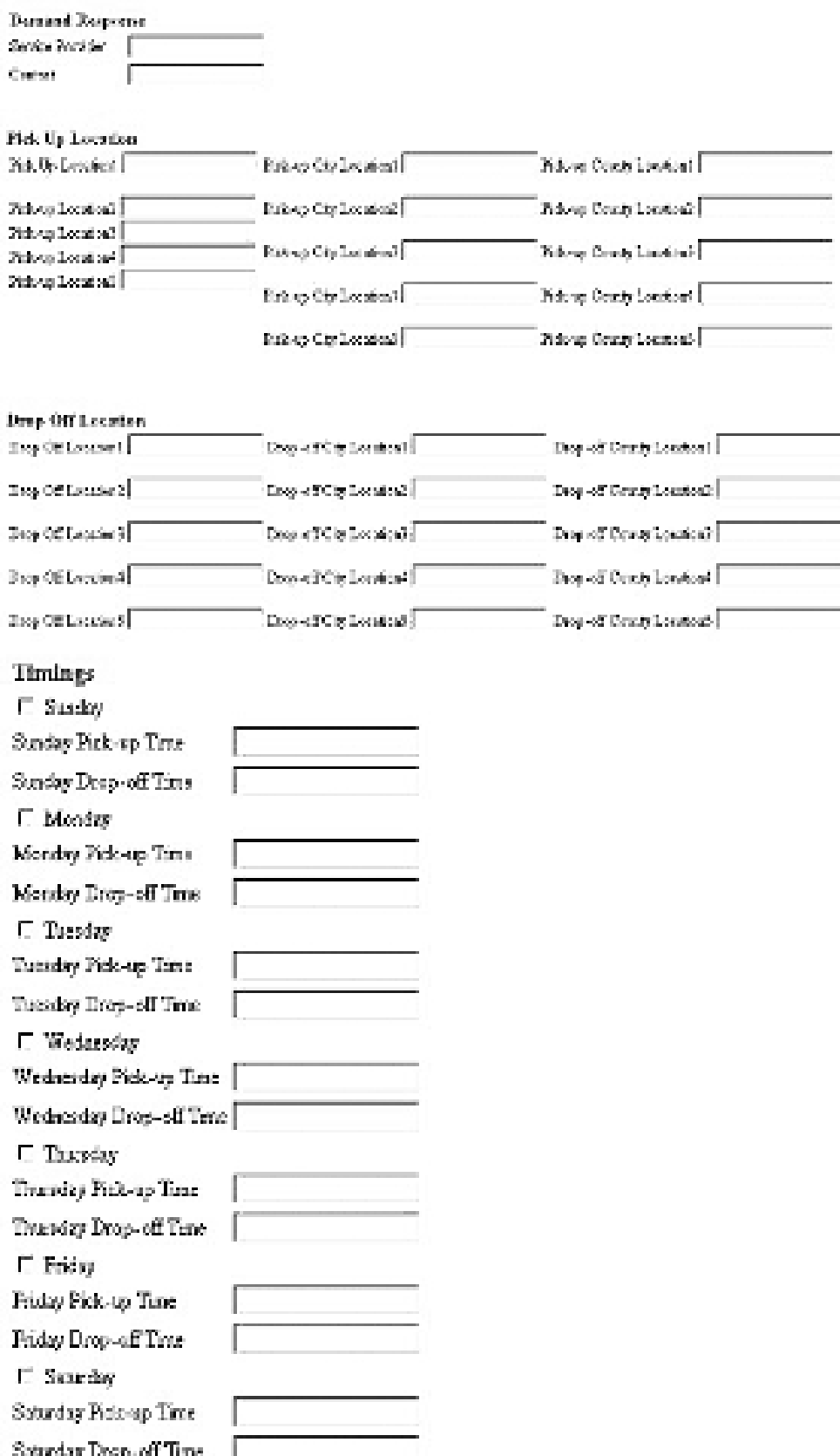


\section{Step 3. Internet-based Dissemination System}

The dissemination of the transportation information for the region is also performed through an Internet-based system. It was decided to focus on this technology because the Internet allowed graphical selection of information and was immediately responsive to changes in the transportation service information contained in the database. This capability ensured the information would not become obsolete as long as the transportation agencies maintained their information, which is expected as transportation providers with outdated information will lose ridership. The Internet-based dissemination system was also considered favorable as access to the Internet potentially exists in residents' homes and definitely exists at public locations such as libraries, employment centers, and other community sites. For individuals lacking Internet access or transportation to public places, a common problem in poor, rural areas, the MIMS data can be disseminated by contacting administrative staff of the transit providers in the region, who have full access to the system.

Initially, a series of Internet pages were developed allowing an individual who wanted to learn about the transportation services to select the day of the week they desired transportation, any eligibility qualification classification, and the town where the service was needed. An option was included that would allow any of these, but not all three, to be entered as no concern, which excluded the option from the search requirement. The initial selection screen is shown in Figure 4 and an example of the output provided to an individual who has selected transportation services in Russellville, Alabama, is shown in Figure 5. 
Figure 4. Initial Screen View of the MIMS

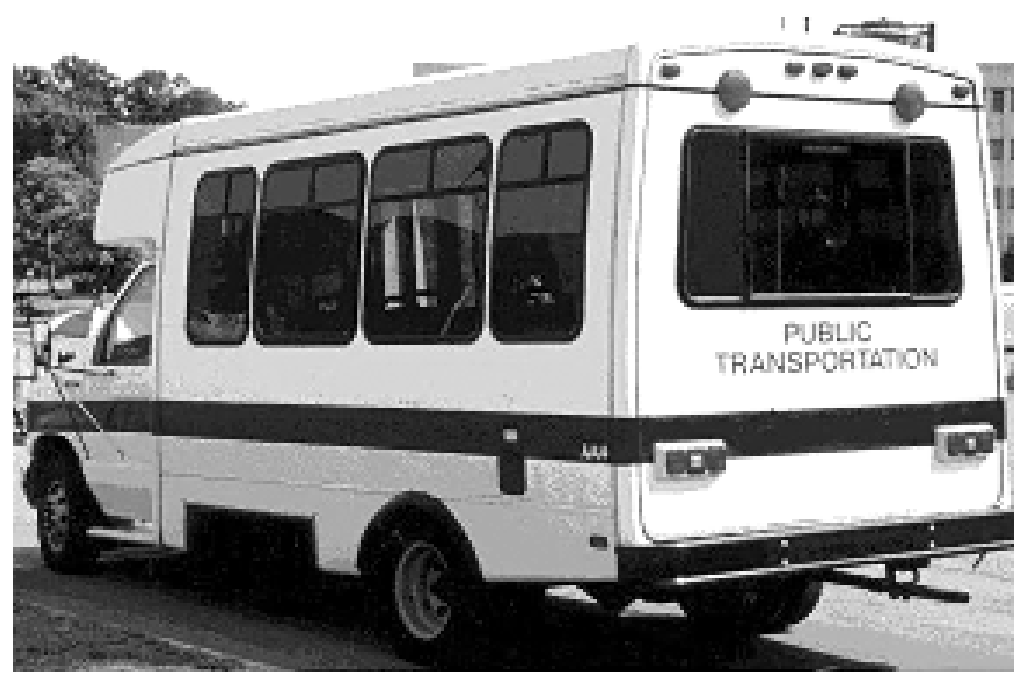

Select Fow Qomy:

\begin{tabular}{|c|c|c|c|c|}
\hline Day & Fliejtlity & & City & \\
\hline Woconsem t & hooromen & - & Mocscen & - \\
\hline $\begin{array}{l}\text { Rondey } \\
\text { Tucidsy } \\
\text { Wedncidsy } \\
\text { Thurseley } \\
\text { Fridoy }\end{array}$ & 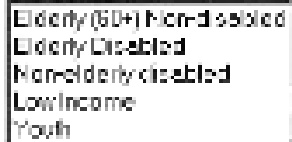 & & 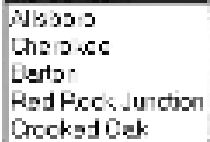 & + \\
\hline
\end{tabular}

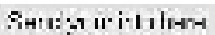




\section{Figure 5. Transportation Service Provider information for Russellville, Alabama}

Cits : Rnssentuille

\begin{tabular}{|c|c|c|}
\hline Orgauizaniau & Phane & Cantatet Persau \\
\hline PILRLM HOWSE, NEC & $255.983-2856$ & TESSTE B.AT.EY \\
\hline 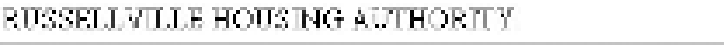 & $256 .-93:-156 \cdot 1$ & TOFN O NEAI. \\
\hline KACA OF THE SLOALS & $\ddot{2} 5 s-i \dot{s}-4 \dot{b} 52$ & HAROLL W. OOX \\
\hline N.V. ALAEALLA COUNCII OF IOCA GCVOBNLENTS & $255-212-60: 7$ & DOELS TDWELL \\
\hline
\end{tabular}

The initial dissemination system was modified, as with the other steps, to reflect the change in data collection from service providers to individual routes. Alterations to the MIMS included the shift from agency queries to specific route queries. The final design provided the individual interested in service two access methods: a graphical method, in which the individual selects the city of interest, and a trip purpose menu, in which the individual selects the type of trip requested. Figure 6 shows the main screen, highlighting the two access methods.

\section{Figure 6. Version 3 Access Screen}

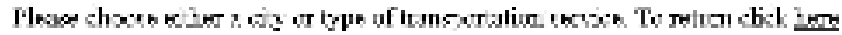

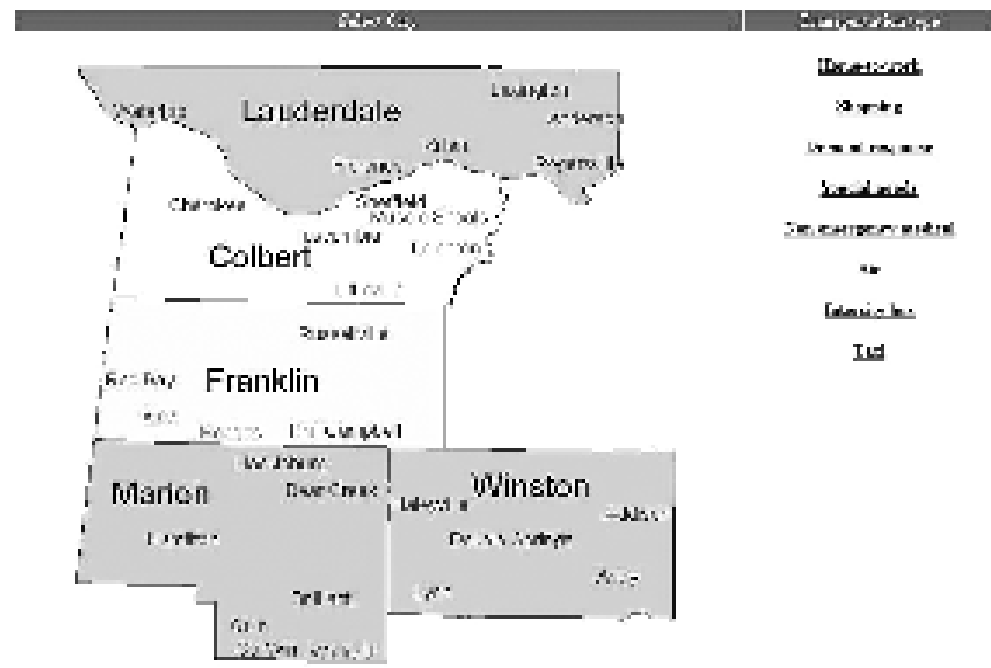


The first access method for the MIMS system is through a locality menu. For this menu, the individual is presented with an interactive map of the region from which they can choose the city where they desire transportation service. This selection will then provide all of the transportation service information available to the individual, segmented into the various types of transportation identified from the trip purpose menu. An example is shown in Figure 7 for Sheffield, Alabama.

\author{
Figure 7. Results for Sheffield, Alabama
}

\title{
Welcome to Sheffield, Alabama
}

\section{Trausportetion type}

Home-to-work

There are ne senise prowiders For City and Coraty Tet

\begin{tabular}{|l|l|l|l|}
\hline Click Itere & ID Number & Service Provider Name & Thoue Number \\
\hline No Reserda & No Recerda & No Resecds & No Rererds \\
\hline
\end{tabular}

Here are the sernice grovider in gocr coung

\begin{tabular}{|c|c|c|c|}
\hline Click Here & II Number & Service Travider Name & Phone Number \\
\hline$\$ 10 \% 2 E 00 \mathrm{PD}$ & 40 & NACOLG & $256-389-0510$ \\
\hline MOONRECOPD & 41 & NACOLG & $256-389-0510$ \\
\hline SHOW REOOPD & 42 & NACOLG & $256-389-0510$ \\
\hline SHOW ZECOPD & 43 & NACOTG & $256-389-0510$ \\
\hline
\end{tabular}

Shovping

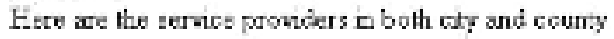

\begin{tabular}{|c|c|c|c|}
\hline Click Here & ID Number & Service Psuvider Name & Pluove Number \\
\hline SHXW & 17 & MACOLO & $256-399-0510$ \\
\hline 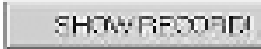 & 16 & $\mathrm{NACOLO}$ & $256-358-0510$ \\
\hline
\end{tabular}


From the information provided by the system, there are currently no home-towork routes originating or terminating in Sheffield. However, there are four hometo-work routes within the County operated by NACOLG (Northwest Alabama Council of Local Governments), the area's Section 5311 provider. For any of the routes available in either the City or County, there is a "show record" button available to obtain additional information. Figure 8 shows the details for one of the home-to-work routes.

\section{Figure 8. Detailed View of a Home-to-Work Route in the System}

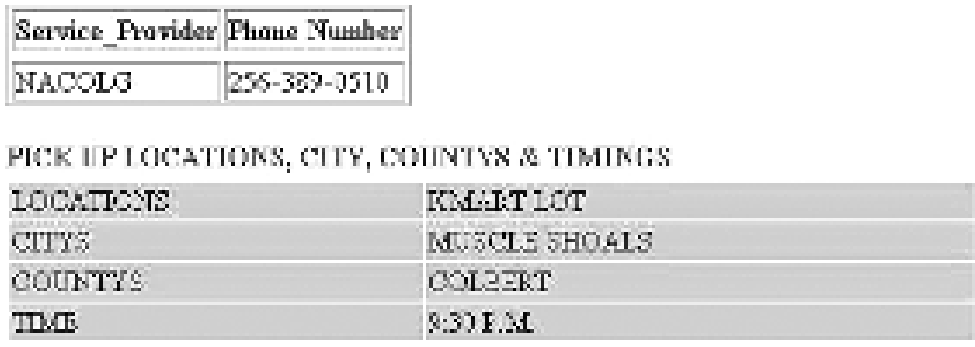

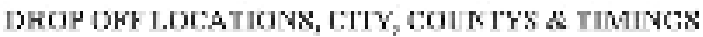

\begin{tabular}{|c|c|}
\hline LoGNTIS:TS & 5 JILLP \\
\hline CIIYs & :UNISVULE \\
\hline cocrNTYE & ArDISOK \\
\hline TDCIE & CY $5 P . M$ \\
\hline
\end{tabular}

WKKK DАЗ

\begin{tabular}{|c|c|}
\hline SU1रास: & $\mathrm{MC}$ \\
\hline MONL $\mu^{2}$ & YES \\
\hline TUTSI $4:$ & MTS \\
\hline deridon $\ldots$ ir & ir $: 3$ \\
\hline THUYSA: & IES \\
\hline FEID $4:^{\circ}$ & YES \\
\hline SkTURI $\dot{r}=$ & $\mathrm{MC}$ \\
\hline
\end{tabular}


The second access method for the MIMS is though a trip purpose menu. This menu itemizes the types of trips that an individual may select and provides a list of specific services available in the region. Types of trip purposes available to select from include:

- Home-to-work routes

- Shopping routes

- Demand response

- Special needs

- Emergency medical

- Nonemergency medical

- Intercity bus

- Regional air

- Taxi.

Upon selection of any of these menu options, the system will advance users to a screen showing a list of available services for the specific type of transportation selected as well as contact information and providers. The results for demand response transportation are shown in Figure 9. From the entire list of demand response route options, the user can then select the ID number for the appropriate route to view a more detailed listing (the ID number is located at the beginning of the line). Figure 10 shows a demand response route with enhanced detail. The dissemination screen provides sufficient information to the individual using the system to make an informed decision as to whether the services offered are capable of meeting their individual needs and agency contact information to learn more about the service or to request service. 


\section{Figure 9. Demand Response Transportation Services}

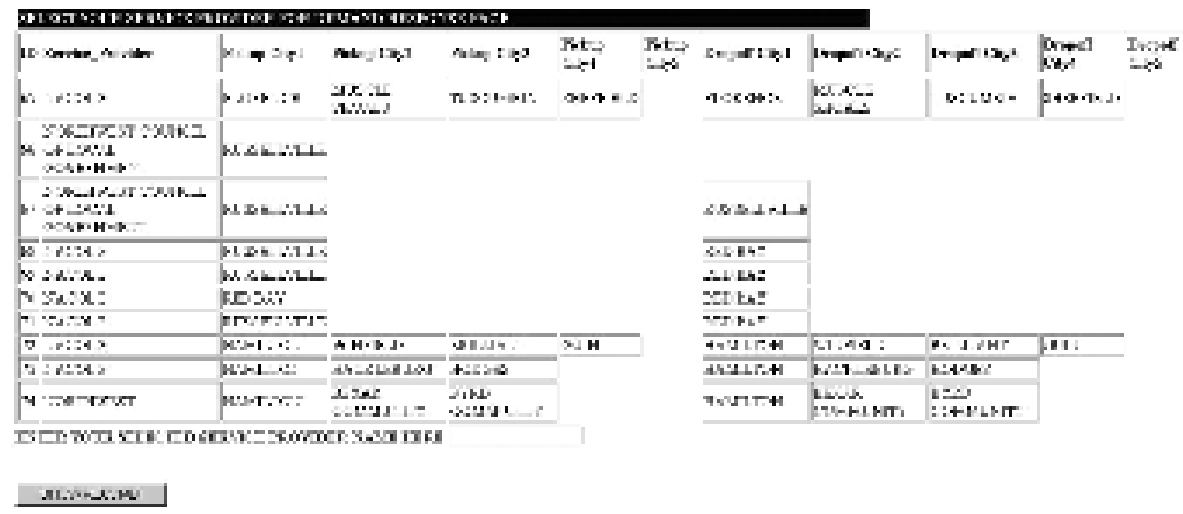

Figure 10. Detailed Information for a Demand Response Route

\begin{tabular}{l|l}
\hline Sarviea_Providar & Phana Nmmhar \\
\hline NACCOLG & 255-385-0510 \\
\hline
\end{tabular}

HICK UP LOCATIONS, CITY, COUXTYS \& TILIE

\begin{tabular}{|c|c|c|c|c|}
\hline LCQCXTIOHS & HMAIITON & & & \\
\hline CTYS & HRistTOS & XIFसID & втпIтй & GLT: \\
\hline corntrs & MARTOH & M:RTOL & WARTOT & W:FTOH \\
\hline Tlus & & & & Q60AMSAK LEL \\
\hline
\end{tabular}

DAOP OFF LOCATIONS, CTY, COUYTYS \& TTME

\begin{tabular}{|c|c|c|c|c|}
\hline LOCNTIOHS & 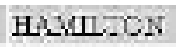 & MINEIELD & BEIILCNS: & GUIN \\
\hline GTYS & IINAII & जमनास्व & 3III:MT: & GUIT \\
\hline cotnsts & KLRTON & TSARTON & NARTOIN & HARTON \\
\hline TIivE & & & & L03TIS EFDTDE \\
\hline
\end{tabular}

WFRK DAYS

\begin{tabular}{|c|c|}
\hline STTNDAF & 100 \\
\hline HONDA: & 10 \\
\hline TUESDA: & NO \\
\hline PEDNTSIAY & 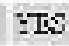 \\
\hline THIREDSY & 170 \\
\hline FRII $A F$ & 170 \\
\hline BAIVKDAY & NO \\
\hline
\end{tabular}




\section{Conclusions and Future Work}

The rural transportation MIMS developed for the northwest Alabama region of Colbert, Franklin, Lauderdale, Marion, and Winston Counties provides a unique method to maintain and access transportation data. The system has been designed to be easily understood by both the transportation agencies responsible for entering and maintaining the transportation service information and the individual user who desires information on the transportation services offered in the region. The completion of the system provides a mechanism to educate the public on transportation services and allows transportation service agencies to understand all of the services available in the region and to help passengers arrange needed transportation services. Currently, the system developed for the case study area is operational and available to the public as a link from the Alabama Rural Transit Assistance Program Internet site (www.alrtap.org). The information in the system continuously evolves as new transportation providers are entering their service information and the system, itself, is being modified to include the entire State of Alabama. In addition, the possibility of establishing a statewide contact number to access MIMS system data for individuals without Internet access is to be examined. Overall, the MIMS is attempting to assist rural transit providers become mobility managers and provide a mechanism for individual travelers to obtain access to a wealth of information related to transportation services and providers.

\section{Acknowledgments}

The author would like to thank the Mack-Blackwell Transportation Center and the Multimodal Bureau of the Alabama Department of Transportation for funding this research. The author would also like to thank all members of the transportation agencies who assisted on this project by supplying the data necessary to construct the system. 


\section{References}

Cambridge Systematics, Inc. 1996. Travel Survey Manual. U.S. Department of Transportation, Federal Highway Administration, Federal Transit Administration, Office of the Secretary, U.S. Environmental Protection Agency.

Shoals Chamber of Commerce, Alabama. http://www.shoalschamber.com/ accessed September 13, 2002.

Tooley, M., J. Gattis, and A. Watts. 2000. The northwest Arkansas transit assessment study. MBTC Document 1103.

Transit Agency Survey Form. Montana rural passenger needs study. http:// www.Isccs.com/projects/MDT/techmemo2/AppA.PDF.

Transit Agency Survey Form Colorado statewide 2000 transit survey update. http:/ /www.Isccs.com/projects/CDOT-TNBS/infosurvey.htm.

United States Census Bureau. www.census.gov accessed July 30, 2001.

\section{About the Author}

Michael D. Anderson (mikea@cee.uah.edu), an assistant professor of civil engineering at the University of Alabama in Huntsville, is working on rural public transportation and transportation forecasting. Dr. Anderson teaches courses in traffic engineering, urban planning, and Geographic Information Systems. He received his Ph.D. from lowa State University. 